\title{
Determination of the mixing layer height from regular lidar measurements in the Barcelona Area
}

\author{
Michaël Sicard ${ }^{* a}$, Carlos Pérez ${ }^{\mathrm{b}}$, Adolfo Comerón $^{\mathrm{a}}$, José María Baldasano ${ }^{\mathrm{b}}$, Francesc Rocadenbosch $^{\mathrm{a}}$ \\ ${ }^{a}$ Universitat Politècnica de Catalunya, Dept. de TSC, Jordi Girona 1, 08034 Barcelona, Spain

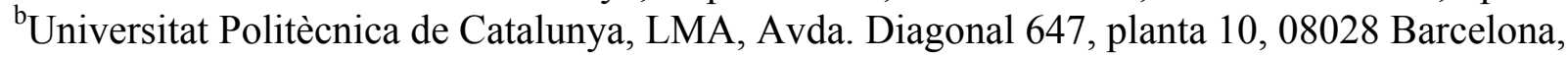 \\ Spain
}

\begin{abstract}
Regular aerosol backscatter measurements using an elastic-backscatter lidar were performed between May 2000 and November 2002 in Barcelona (Spain), in the frame of EARLINET (European Aerosol Research Lidar Network). The mixing layer height, required to understand the chemical and physical processes taking place in the low troposphere, was one of the major parameters to be retrieved. Three analytic definitions of the ML height have been tested using the range squared-corrected lidar signal: (1) the minimum of its first derivative, (2) the minimum of its second derivative, and (3) the minimum of the first derivative of its logarithm. The strong coastal and orographic influences and the climatological settling of Barcelona determine the complexity of its atmospheric boundary layer dynamics and the high heterogeneity of the lidar signals. Therefore, single lidar analyses do not allow an unambiguous determination of the mixing layer height in many cases and complementary data are needed, such as synoptic maps, backtrajectories, radiosoundings and solar irradiance profiles. The resulting mixing layer heights were compared to radiosoundings, and the second method was found to give statistically the best results. This definition was used to process the whole dataset. A number of 162 days and 660 profiles were examined. The mixing layer height was inferred in cases such as low clouds, Saharan dust events and sea breeze and mountain induced recirculation. Variations between 300 and $1450 \mathrm{~m}$ were observed over the three years.
\end{abstract}

Keywords : mixing layer height, lidar profiles, radiosoundings, complex orography

\section{INTRODUCTION}

The atmospheric boundary layer $(\mathrm{ABL})$ can be defined as the part of the troposphere that is directly influenced by the presence of the earth's surface. The mixing height $(\mathrm{MH})$ is the height of the mixing layer (ML) which is the layer adjacent to the ground over which pollutants or any constituents emitted within this layer or entrained into it become vertically dispersed by convection or mechanical turbulence within a time scale of about an hour ${ }^{1}$. The MH is a key parameter to characterize the structure of the ML. Different ways exist to determine or estimate the MH. Radiosoundings are the most common data source to retrieve the MH based on wind, temperature and humidity profiles. However, each balloon is lost in the atmosphere and because of its high cost, measurements are only taken twice daily at specified synoptic times (00 UTC, 12 UTC).

Active remote sensing systems such as lidars use aerosols as tracers of the ABL dynamics. The optical power measured by a lidar device is proportional to the aerosol content of the atmosphere. For example, the greater aerosol and moisture content in the ML than in the free troposphere (FT) causes more laser light scattering and the boundary between the two layers can be easily detected ${ }^{2}$. Thus, lidars have been increasingly used to estimate the $\mathrm{MH}^{2-5}$. However, interpreting data from lidars is often not straightforward, because the detected layers are not always the result of ongoing vertical mixing, but may originate from advective transport or past accumulation processes ${ }^{6}$. While over land surfaces in highpressure regions the ML has a well-defined structure that evolves with the diurnal heating cycle, in coastal regions with complex orography as Barcelona, mesoscale phenomena as sea-land breezes and mountain-induced winds modify the ML flow generating circulations in conjunction with diurnal heating cycles. The more usual synoptic situations affecting the Barcelona area are westerly and northwesterly flows, and typical summertime weak pressure gradient conditions $^{7-8}$. During these summertime episodes, layering and accumulation of pollutants occur all over the region ${ }^{9-10}$.

\footnotetext{
*msicard@tsc.upc.es; phone 34934017 758; fax: +34 934017 200; http://www.tsc.upc.es
} 
In addition to these regional recirculation, synoptic scale meteorology induces frequent outbreaks of Saharan dust in summer ${ }^{11}$.

In the frame of EARLINET ${ }^{12}$ (European Aerosol Research Lidar Network), 21 lidar stations performed regular lidar measurements from May 2000 to November 2002 to provide a climatological database of the vertical and horizontal distribution of aerosols over Europe. Among other subjects, the network studies the aerosol properties in the lower troposphere and more particularly in the ABL at different time scales (diurnal and seasonal cycle). In this context, the MH was one of the major parameters to be retrieved. Several retrieval methods have been tested in order to estimate the MH from the whole climatological database.

\section{THE BARCELONA AREA: OROGRAPHY AND METEOROLOGICAL SETTLING}

Barcelona is located on the shores of the Mediterranean Sea, on the northeastern corner of the Iberian Peninsula (IP). The meteorology and the origin of the air masses arriving at the IP are highly influenced by the Azores high pressure system which is located over the Atlantic Ocean and that intensifies during the warm season inducing very weak pressure gradient conditions all over the region. The major orographic features that influence the flows arriving at the Barcelona air basin are the Pyrenees and the Ebro valley. The Pyrenees range from $2000 \mathrm{~m}$ to $3000 \mathrm{~m}$, acting as a natural barrier of the flows and producing important orographic forcings into the low troposphere. The Ebro valley has a length of $350 \mathrm{~km}$, channelling the flows of the Cantabric sea to the Mediterranean or vice versa. The nearby orography of the region is dominated by four main features arranged parallel to the coastline: the coastal plain, the coastal mountain range $(500-700 \mathrm{~m})$ the pre-coastal depression, and the pre-coastal mountain range (700-1700 $\mathrm{m})$.

\section{THE BARCELONA LIDAR SYSTEM AND EARLINET}

A transportable, steereable lidar system allowing three-dimensional scans has been developed at the Universitat Politècnica de Catalunya (UPC) ${ }^{13}$. A Raman channel is currently being added to the system ${ }^{14}$. The present system is based on a Nd:YAG laser working at the 1064-nm fundamental wavelength and at the 532-nm second harmonic, delivering pulses of equal energy $(160-\mathrm{mJ})$ and 6-ns duration with a $20 \mathrm{~Hz}$ PRF. The photoreceiver is based on an avalanche photodiode (APD) with a wide spectral response (its quantum efficiency is about the same at both wavelengths). One changes the wavelength by placing manually the corresponding interference filter in front of the APD. The emission and reception axes are different so that a blind zone is observed between 0 and $250 \mathrm{~m}$. However the overlap factor reaches 1 rapidly.

The Barcelona lidar station forms part of the EARLINET. Regular lidar measurements were undertaken from May 2000 to November 2002 on preselected dates regardless of the weather conditions to provide an unbiased climatological database of the horizontal and vertical distribution of aerosols over Europe ${ }^{12}$. For this reason a common schedule of three measurements per week was agreed. Measurements were performed on Monday at 1400 LST (local solar time) +/1 hour and at sunset $-2 /+3$ hour and on Thursday at sunset $-2 /+3$ hour. Furthermore, the network performed diurnal cycle measurements under unperturbed weather conditions, ideally under high-pressure systems to allow simultaneous observations at different stations and quantify the behaviour of aerosols at the regional scale.

All lidar measurements were made at the UPC campus, south west of Barcelona (41.39 N, 2.12 E, $115 \mathrm{~m}$ above sea level) at the wavelength of 532 or $1064 \mathrm{~nm}$. Sequences of 1-minunte duration (1200 shots) were recorded. The 30minute integrated profiles used in this analysis are the average of 30 consecutive 1-minute profiles.

\section{METHODS USED IN THE DETERMINATION OF THE MH}

The optical power measured by a lidar is proportional to the signal backscattered by particles and molecules present in the atmosphere. The lidar signal can be expressed as:

$$
\mathrm{S}(\mathrm{r})=\frac{\mathrm{K}}{\mathrm{r}^{2}} \cdot\left[\beta^{\mathrm{a}}(\mathrm{r})+\beta^{\mathrm{m}}(\mathrm{r})\right] \cdot \mathrm{T}(\mathrm{r})^{2}+\mathrm{S}_{0}
$$

where $\beta^{\mathrm{a}}$ and $\beta^{\mathrm{m}}$ are, respectively, particular and molecular backscatter coefficients, $\mathrm{K}$ is the system constant, $\mathrm{T}$ is the atmospheric transmission, $\mathrm{r}$ is the range between the laser source and the target, and $\mathrm{S}_{0}$ is the background signal. The range-squared-corrected signal (RSCS) is then defined as:

$$
\mathrm{RSCS}=\left(\mathrm{S}-\mathrm{S}_{0}\right) \mathrm{r}^{2}
$$


The lidar signal shows a strong backscattering within the ML, which decreases through the entrainment zone and becomes weak in the FT. These contrasts are the basis of the lidar estimations of the MH used in this paper. Since a large climatological database of temporally integrated profiles needs to be analysed, the use of a method based on the temporal variations of the profiles, as it is the case of the variance method ${ }^{15}$ is not possible. Only methods not requiring temporal evolution of the ML are suitable for this kind of study. Three methods have been tested in order to estimate the $\mathrm{MH}$ from the large database:

The first method is the gradient method (GM). It looks for the altitude, $\mathrm{h}_{\mathrm{GM}}$, at which the minimum of the first derivative of the RSCS, i.e. the minimum of the gradient profile, is reached:

$$
\mathrm{h}_{\mathrm{GM}}=\min _{\mathrm{r}}\left[\frac{\partial \mathrm{RSCS}}{\partial \mathrm{r}}\right]
$$

The second method is the inflection point method (IPM). It consists in finding the altitude, $\mathrm{h}_{\text {IPM }}$, at which the minimum of the second derivative of the RSCS is reached. This minimum corresponds to the inflection point of the first derivative. It is usually located below $\mathrm{h}_{\mathrm{GM}}$ :

$$
\mathrm{h}_{\mathrm{IPM}}=\min _{\mathrm{r}}\left[\frac{\partial^{2} \mathrm{RSCS}}{\partial \mathrm{r}^{2}}\right]
$$

The third method, so called logarithm gradient method (LGM), consists in finding the altitude, $\mathrm{h}_{\mathrm{LGM}}$, at which the minimum of the first derivative of the logarithm of the RSCS is reached:

$$
\mathrm{h}_{\mathrm{LGM}}=\min _{\mathrm{r}}\left[\frac{\partial \ln (\mathrm{RSCS})}{\partial \mathrm{r}}\right]
$$

Figure 1 shows a typical averaged profile obtained on 16 October 2000 from 1202 to 1232 UTC. The MH retrieved by the three methods are reported on the figure.

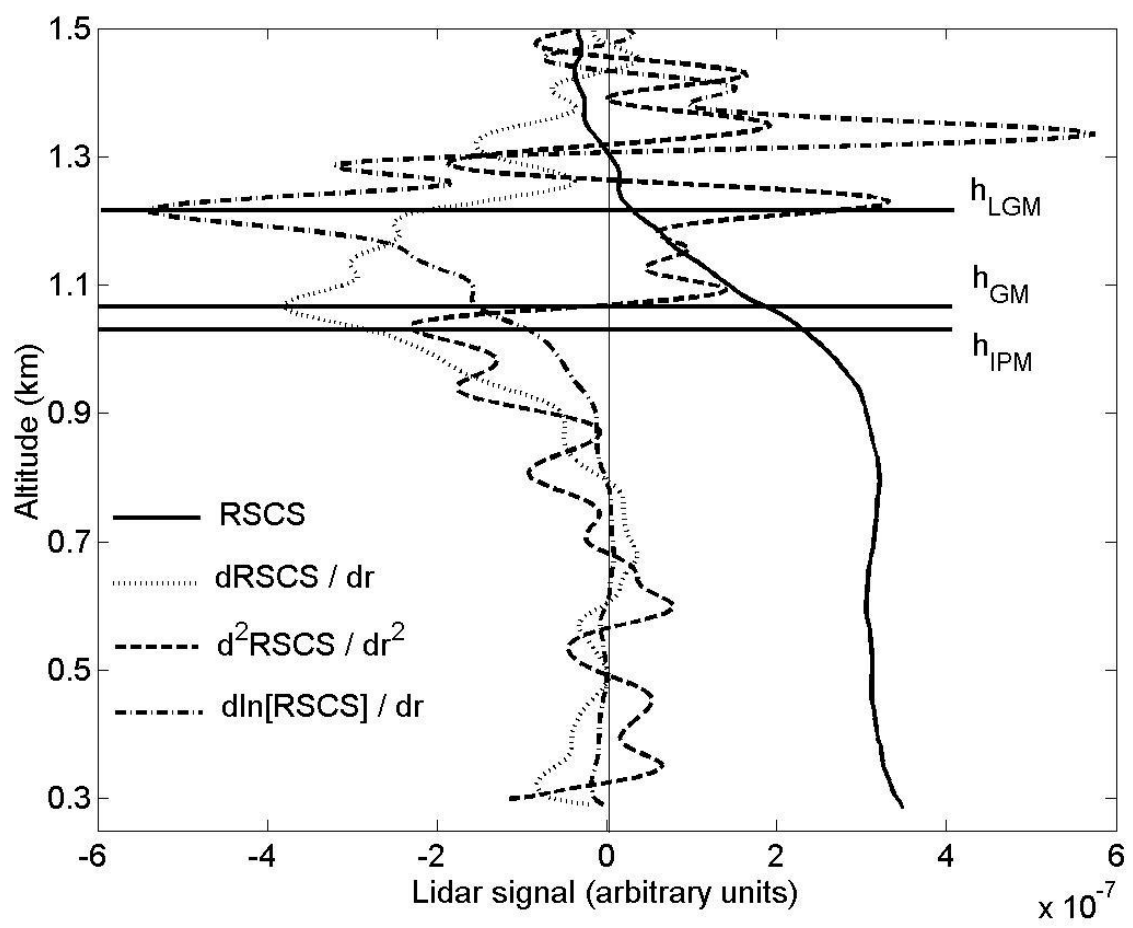

Fig. 1: 30-minute integrated RSCS profile on 16 October 2000 from 1202 to 1232 UTC.

However, things might be more complicated because for each method the minimum cannot be well defined or several minima exist over an extended altitude range. Therefore, if possible one should correlate the altitude of the minima with the temporal evolution of the aerosol layers. This is detailed in Section 6.1. Often the ML can be better identified if a time series of profiles is available. Additional radio soundings or water vapour profiles can also help identifying the 
'real' ABL. In the morning, one often has to distinguish between the newly developing ML and the ABL from the day before which is still present and in this case called residual layer (RL). This effect of two layers is described in Stull ${ }^{16}$. If several layers exist that are clearly separated, only the lowest layer is labelled ML. In the morning, when both ML and the RL on top of it may exist, these layers are typically well connected, but 2 local minima are observed.

The lidar dataset covers the years 2000, 2001 and 2002. The radiosoundings were launched at 0000 and 1200 UTC with an incertitude known to be of $-20 /+10$ minutes. At $1200 \mathrm{UTC}$, the ABL can change quite rapidly and the 30-minute integrated profiles eventually show large differences against 5-minute and 15-minute integrated profiles. Since the incertitude on the hour of the radiosounding launches is not negligible, an analysis of the 5-minute integrated profiles could lead to large errors in the comparison with the radiosoundings due to the eventual large time differences. Therefore, 15-minute integrated lidar profiles with starting times between $-20 /+10$ minutes around 1200 UTC were used for comparison with radiosoundings when possible.

\section{COMPARISON OF THE MH FROM LIDAR MEASUREMENTS AND SOUNDINGS}

Everyday the Meteorological Service of Catalonia performs 2 radiosoundings at 0000 and 1200 UTC. Measurements of temperature, pressure, relative humidity, wind speed and direction are available. The potential temperature, $\theta$, at the altitude $\mathrm{z}$ is defined as:

$$
\theta(z)=T(z)\left(\frac{P_{s}}{P(z)}\right)^{\kappa}
$$

where $\mathrm{T}$ is the temperature in Kelvin, $\mathrm{P}_{\mathrm{s}}$ the standard surface pressure $\left(\mathrm{P}_{\mathrm{s}}=1.01325\right.$ bar $), \mathrm{P}$ the real pressure and $\kappa=\mathrm{R}_{\mathrm{g}} /$ $\mathrm{C}_{\mathrm{p}}=0.286$ for a diatomic ideal gas.

\subsection{The bulk Richardson number method}

The bulk Richardson number method ${ }^{17}$ can be used both in convective conditions and in mechanical turbulence. The Richardson number, $\mathrm{R}_{\mathrm{ib}}$, is calculated as:

$$
\mathrm{R}_{\mathrm{ib}}(\mathrm{z})=\frac{\mathrm{g}\left(\mathrm{z}-\mathrm{z}_{0}\right)}{\theta(\mathrm{z})} \frac{\left[\theta(\mathrm{z})-\theta\left(\mathrm{z}_{0}\right)\right]}{\mathrm{u}(\mathrm{z})^{2}+\mathrm{v}(\mathrm{z})^{2}}
$$

where $\mathrm{g}$ is the acceleration due to gravity, $\mathrm{z}_{0}$ the height of the surface, and $\mathrm{u}$ and $\mathrm{v}$ the zonal and meridian wind components, respectively. The ABL top is defined as the height where the Richardson number becomes equal or larger than the so-called critical Richardson number, i.e. $\mathrm{R}_{\mathrm{ib}}>\mathrm{R}_{\mathrm{ibc}}$, where $\mathrm{R}_{\mathrm{ibc}}$ is the critical bulk Richardson number. A value of 0.21 is taken for $R_{i b c}$. Beyond this critical value of $R_{i b}$ the atmosphere can be considered fully decoupled from the ABL.

\subsection{The simple parcel method}

The simple parcel method ${ }^{18}$ has turned out to be most reliable in convective situations. The dry adiabate is followed from the measured surface temperature (or an expected maximum temperature) to its intersection with the temperature profile from the radiosounding. The $\mathrm{MH}$ is taken at the equilibrium level of an air parcel with the temperature. This method was refined by several authors ${ }^{19-21}$ by adding an excess temperature (advanced parcel method). Since under convective conditions a superadiabatic layer is usually found near the ground, the simple parcel method also implicitly applies an excess temperature. In this section, and for the purpose of comparison with the bulk Richardson number method, the simple parcel method is applied to the radiosoundings data.

\subsection{Comparison of both methods}

Figure 2 shows how both methods perform on the case of 16 October 2000. The $57-\mathrm{m}$ difference is not significant on this single case.

During the three years of measurements, the number of temporal coincidences between radiosoundings and lidar measurements, as described in section 4, is 29. Figure 3 represents the $\mathrm{MH}$ retrieved by the Richardson method and the simple parcel method for these 29 days. The agreement between both methods is good: the correlation coefficient is 0.997 and the standard deviation is $28 \mathrm{~m}$.

Even though the comparisons were performed mainly at noon, the wide range of MH detected (150 - $1750 \mathrm{~m})$ assesses the reliability of such comparison. The two points around $150 \mathrm{~m}$, even physically doubtful for a MH at $1200 \mathrm{UTC}$ over 
Barcelona, were kept because both profiles of $R_{i b}$ and $\theta$ were similar in shape to the ones shown in Figure 2. The fact that the simple parcel method gives slightly smaller heights probably comes from the missing excess temperature term in cases dominated more by mechanical turbulences than by convective situations. Thus, the lidar profiles were then compared to the MH retrieved by the Richardson number method.
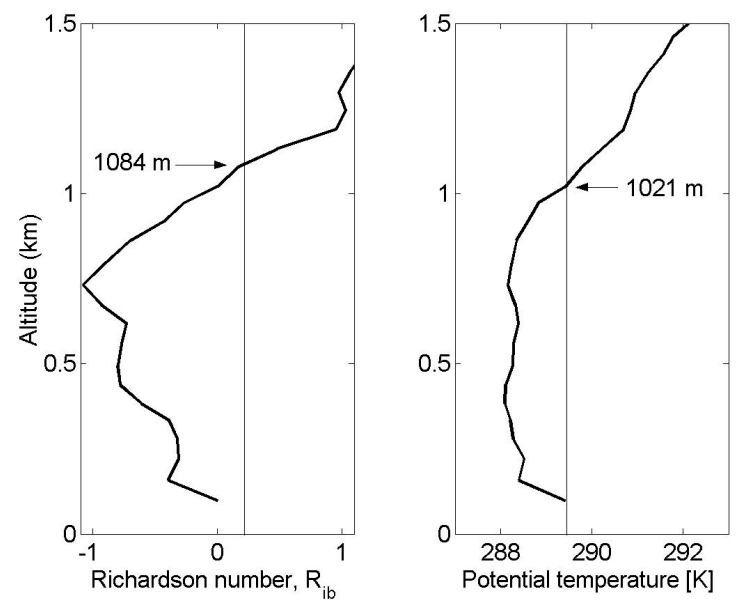

Fig. 2: Richardson number and potential temperature profiles from radiosounding measurements made on 16 October 2000 at 1200 UTC. The Richardson number method retrieves a $\mathrm{MH}$ of $1084 \mathrm{~m}$; the simple parcel method retrieves a $\mathrm{MH}$ of $1021 \mathrm{~m}$.

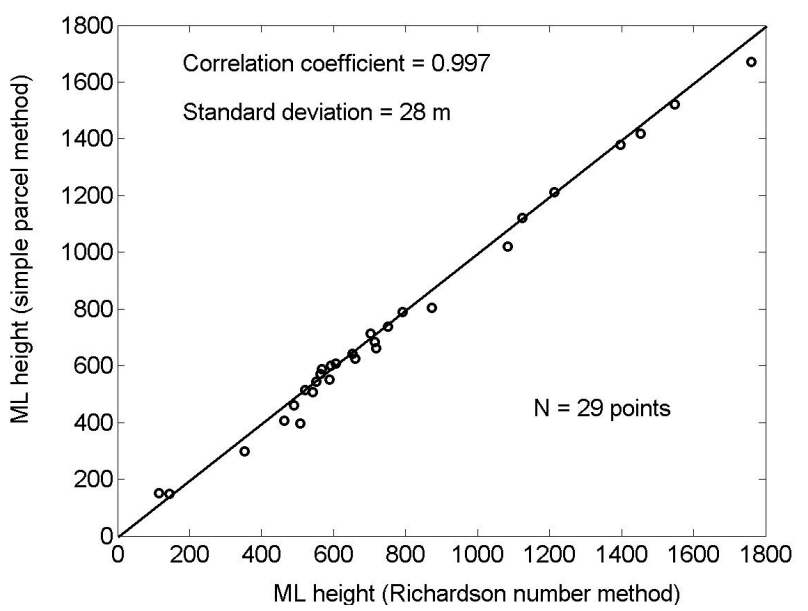

Fig.3: Comparison of the $\mathrm{MH}$ retrieved from radiosoundings by the Richardson number method and the simple parcel method.

\subsection{Comparison of the MH retrievals from radiosoundings and lidar measurements}

From the 29 coincidences between lidar profiles and radiosounding launches, finally 20 lidar profiles were processed by the three analysis methods. The reasons for discarding the other 9 cases are the following:

- Clouds occulting the ABL top,

- Aerosol layer on top of the ML coupled with the ML,

- The MH is underneath the useful lidar signal (before the overlap reaches 1),

- One of the methods exhibits too many negative peaks without crossing the $y=0$ axis.

The results of the comparison between the lidar MH and the radiosounding MH are shown in Figure 4. For each of the lidar analysis methods, good agreement with correlation coefficients of $0.963,0.969$ and 0.979 , respectively, was found for the GM, the IPM and the LGM. The smallest standard deviation is found for the IPM, with a value of $82 \mathrm{~m}$, whereas it is equal to 89 and $101 \mathrm{~m}$, respectively, for the GM and the LGM. Both the GM and LGM seem to retrieve higher MH than the IPM, which is normal since the inflexion point of the first derivative is usually found just before its minimum (for the LGM, this is also true: only the distances change, not the relative position of the points between each other).

\section{RESULTS AND DISCUSSION}

\subsection{Data process}

To fully test the IPM and to identify its advantages and limitations, the analysis was extended to all the lidar data available in Barcelona over the years 2000, 2001 and 2002. There are a total of 162 measurement days with 66030 minute integrated profiles. In many cases, and for the reasons cited in the introduction, a multi-layering is observed. Therefore, an analysis based only on the lidar profiles is not sufficient to estimate the MH without ambiguity: complementary data, such as solar irradiance profiles, backtrajectories, synoptic maps and radiosoundings, were used. The diurnal cycle on 30 May 2002 (Figure 5) is a clear example of the difficulties that often appear when the previous 


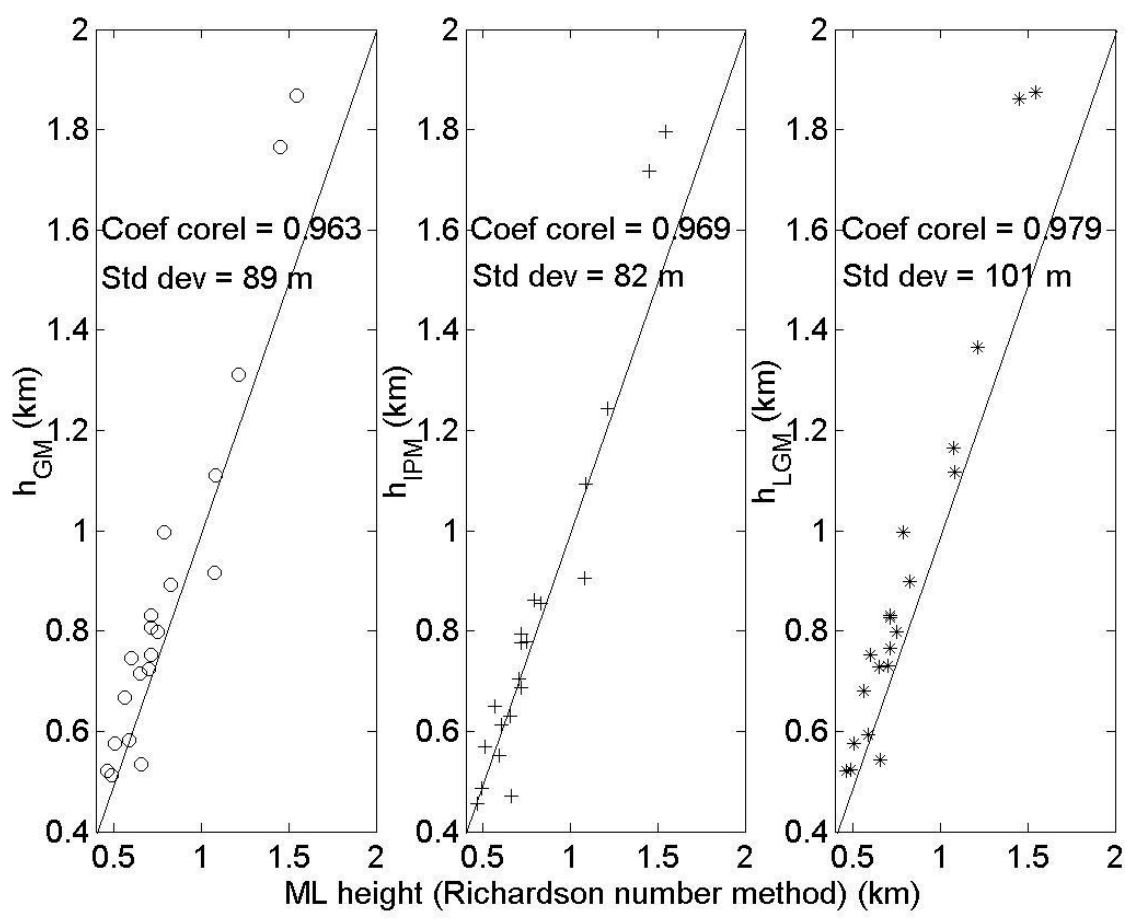

Fig. 4: Comparison of $\mathrm{h}_{\mathrm{GM}}, \mathrm{h}_{\mathrm{IPM}}$ and $\mathrm{h}_{\mathrm{LGM}}$ with the $\mathrm{MH}$ retrieved from radiosoundings by the Richardson number method. In the middle of the figure is reported the correlation coefficient and the standard deviation between the measurements.

methods are applied to the lidar profiles. Figure 5 shows the RSCS profiles, together with the profiles from the 3 methods at $0827,1139,1222,1426$, and 1543 UTC. Each profile shows a multi-layer structure. Figure 5a features the development of the ML at 0827 UTC. An elevated layer is present at about $1000 \mathrm{~m}$, which is fully decoupled from the ML. At this time, if one first looks at the first derivative, there is no ambiguity in the retrieval of the MH: the highest negative peak of the second derivative just below $\mathrm{h}_{\mathrm{GM}}$ determines the $\mathrm{MH}$. Note that in this case, $\mathrm{h}_{\mathrm{IPM}}$ is not the absolute negative peak of the second derivative (around $540 \mathrm{~m}$ ) but the highest negative peak just below $\mathrm{h}_{\mathrm{GM}}($ at $651 \mathrm{~m}$ ). Figure $5 \mathrm{~b}$ features the RSCS profile and the results from the 3 methods at 1139 UTC. The inflexion point corresponding to the highest negative peak of the first derivative gives the $\mathrm{MH}$, which is located at $630 \mathrm{~m}$. The top of the first elevated layer is located at $890 \mathrm{~m}$. At 1222 UTC (Figure 5c), the IPM only would lead to a MH of $580 \mathrm{~m}$. However, the GM indicates without any ambiguity that $\mathrm{h}_{\mathrm{GM}}$ is $740 \mathrm{~m}$, hence the highest negative peak from the IPM is just below at $704 \mathrm{~m}$. Note that here the $\mathrm{MH}$ is given not by the first highest negative peak from the second derivative but by the second one. At 1426 UTC (Figure 5d), the upper layer settles by subsidence and progressively gets connected to the ML. Like in the 0827 UTC case, the highest negative peak of the second derivative just below $\mathrm{h}_{\mathrm{GM}}$ gives a MH of $566 \mathrm{~m}$. At $1543 \mathrm{UTC}$ (Figure 5e), the upper layer is almost completely coupled to the ML and even showing higher RSCS values, but a first small decrease in the RSCS still allows the detection of the MH $(524 \mathrm{~m})$. This situation points out the importance of following the temporal evolution of the ML along the day. However, in the climatological context, if we had considered a unique 30-minute measurement as in Figure 5e, one could state that the $\mathrm{MH}$ is located at $832 \mathrm{~m}$ arguing that the lowest minimum could be due to inhomogeneities within the ML. Thus, the diurnal cycle (Figure 6) allows following the connection between the ML and the upper layer, and locating the proper minimum.

In all these examples, to be sure to present physically meaningful results, a cross-comparison of the temporal evolution of the MH was made. This means that after the first evaluation of the temporal variations of the MH, the plot of Figure 6 is made to check the consistency between successive heights. Figure 6 shows the temporal variation of the lidar signal on 30 May 2002. For example, the radiosounding indicates a MH of $725 \mathrm{~m}$ at 1200 UTC. The MH at 1222 UTC cannot be the height of the first minimum of the second derivative at about $600 \mathrm{~m}$, nor the second layer at about $1000 \mathrm{~m}$. In that case, the radiosounding considerably helps, but a cross-comparison of the temporal evolution of the MH (Figure 6) would also indicate that these 2 alternatives $(600$ and $1000 \mathrm{~m})$ are not possible regarding the previous $\mathrm{MH}$.

In the particular case of 30 May 2002, the sequences from 1222 to 1252 UTC in Figure 6 seem to be split in 2: a first 
group of profiles with a clear $\mathrm{MH}$ at around $725 \mathrm{~m}$, and a second group with a ABL height around $600 \mathrm{~m}$. In that case, the IPM is the only method able to detect both peaks (at 600 and at $725 \mathrm{~m}$ ). The 2 gradient methods detect both peaks but in between do not cross the $\mathrm{x}=0$ axis; therefore only one peak is the solution (the strongest one around $725 \mathrm{~m}$ ).
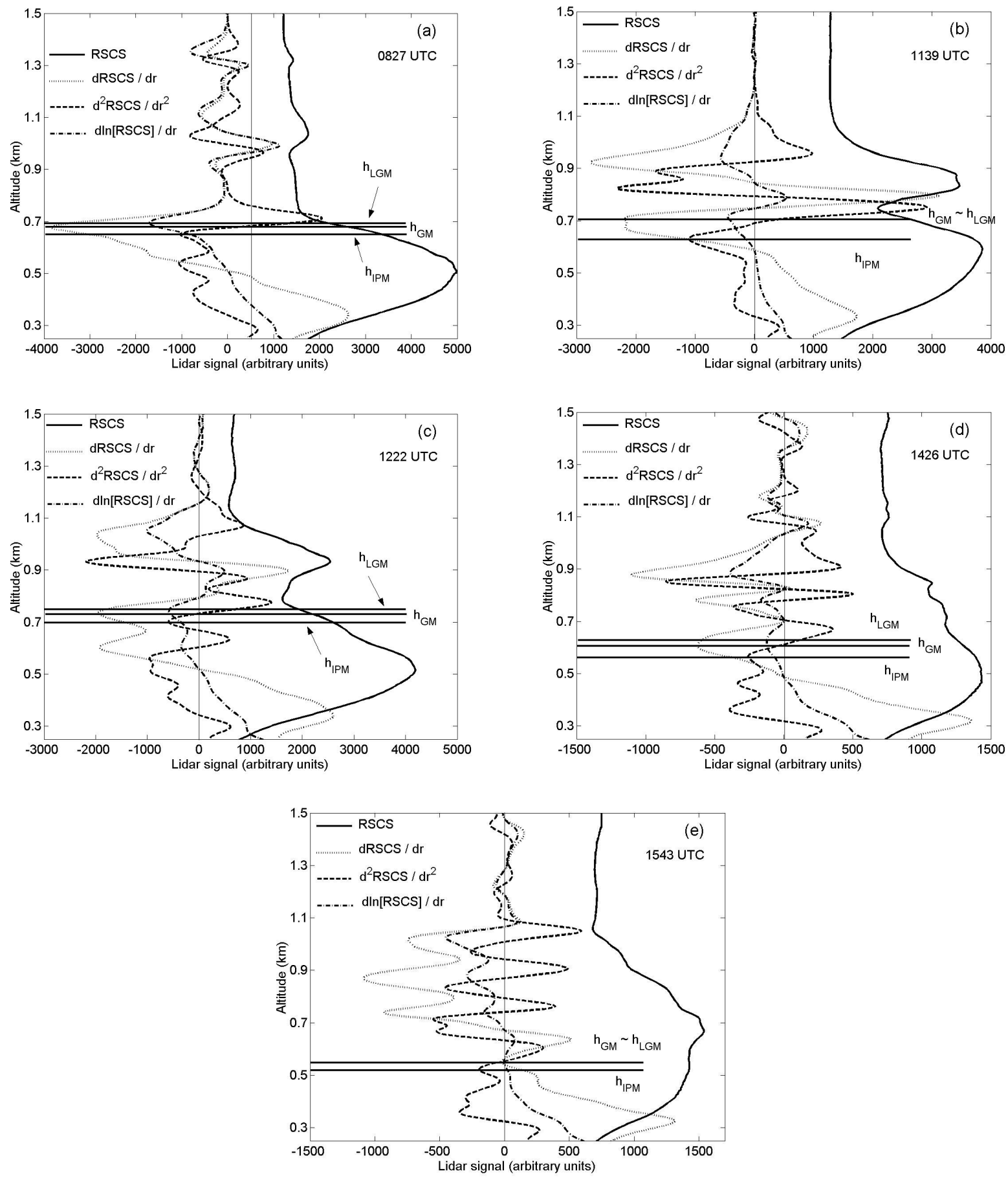

Fig. 5: 30-minute integrated RSCS profiles on 30 May 2002 at (a) 0827, (b) 1139, (c) 1222, (d) 1426, and (e) 1543 UTC.

Looking at the solar irradiance profile (Figure 7a), a small decrease in the global solar irradiance is observed from 1200 to 1300 UTC. This decrease might explain the sudden fall of the MH around 1237 UTC (at half time of the measurements). 


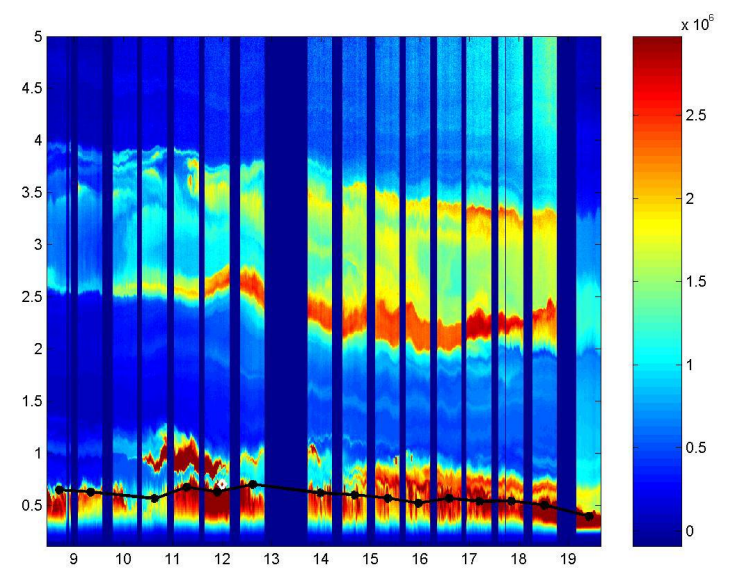

Fig. 6: 1-minute resolution diurnal cycle of the RSCS on 30 May 2002. The black dots indicate the MH retrieved by the IPM. The white diamond indicates the MH measured by radiosounding at 1200 UTC.
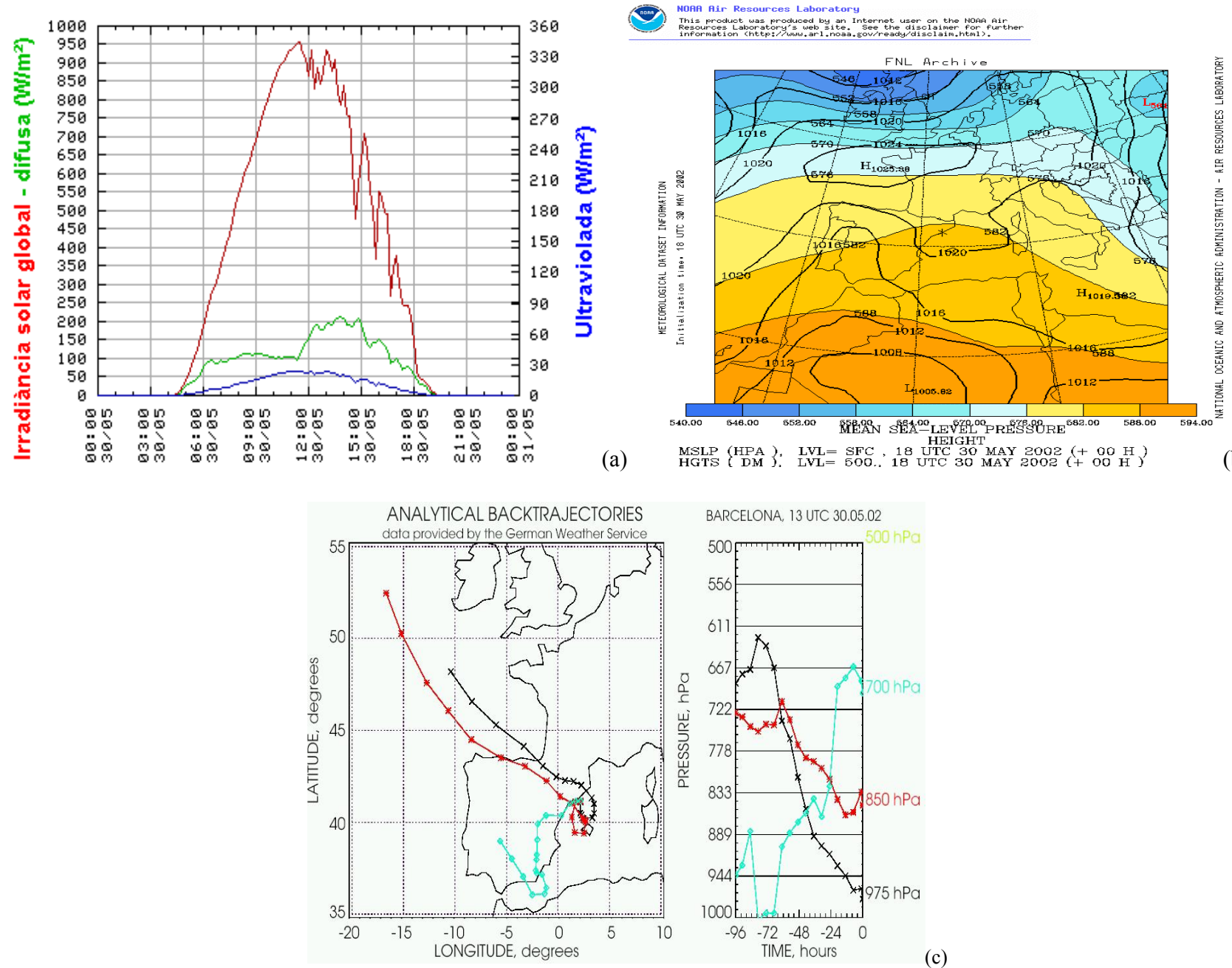

Fig. 7: (a) Solar radiation over Barcelona versus time; (b) MSL pressure and $500 \mathrm{hPa}$ geopotential height at 1800 UTC; (c) Backtrajectories at 1300 UTC. 
This case highlights the drawback of the integration time on the MH retrieval accuracy. Within 30 minutes, the MH can change significantly. However, the IPM will detect in the 30-minute integrated profile only one "averaged" height.

When applying the methods to single 30-minute integrated profiles without the diurnal evolution information, the knowledge of the synoptic situation is essential to better estimate the MH. In Barcelona, the absence of large scale forcing due to very weak pressure gradients and the development of mesoscale flows related to the daily heating and cooling cycle (sea breezes, mountain-induced winds, valley winds and the Iberian thermal low) are summertime recurrent weather patterns. During these episodes layering and accumulation of pollutants occur all over the region. The temporal variation of the solar irradiance during that day (Figure 7a) allows discarding the presence of clouds on top of the ML. Clouds can mask the top of the ML or can bias the measured height. The surface synoptic chart for the 30 May 2002 at 18 UTC features a very weak pressure gradient over the Iberian Peninsula and the Western Mediterranean Basin, and the development of the Iberian thermal low (Figure 7b). The stagnant conditions appear clearly depicted in Figure 7c where 4-day backtrajectories arriving at 700, 850 and $975 \mathrm{hPa}$ show very short paths. These conditions indicate the possible presence of upper aerosol layers coupled to the ML.

\subsection{Mixing layer height in Barcelona between 2000 and 2002}

Among the 660 measurements over 162 days, a comparison of the MH could be made only for a certain portion of the diurnal cycle. We have chosen the period of maximum insolation running from 1000 to 1500 UTC, which corresponds to the unstable thermal stratification. Figure 8 shows the MH in Barcelona retrieved by the IPM over the period 20002002. We have distinguished 2 seasons: summer (from April to September) and winter (from October to March). The MH oscillates between 300 and $1450 \mathrm{~m}$ in summer and between 390 and $1420 \mathrm{~m}$ in winter. The standard deviation for this portion of the day is 180 and $256 \mathrm{~m}$, respectively in summer and winter. One could expect higher values in summer due to enhanced convection but it is not the case. In Figure 8, no significant differences are observed between summer and winter. Furthermore, the average $\mathrm{MH}$ in summer is even smaller than the average $\mathrm{MH}$ in winter. In coastal regions in summer, a thermal internal boundary layer (TIBL) forms when cool marine air is advected onshore, and the lowest portion becomes heated from below by the warm land surface. The TIBL generally does not extend all the way to the top of the marine air associated with the intruding air mass, so the remainder of the cool air mass above the TIBL and below the air flowing from the continent back to the sea, acts as a barrier for the TIBL vertical development.

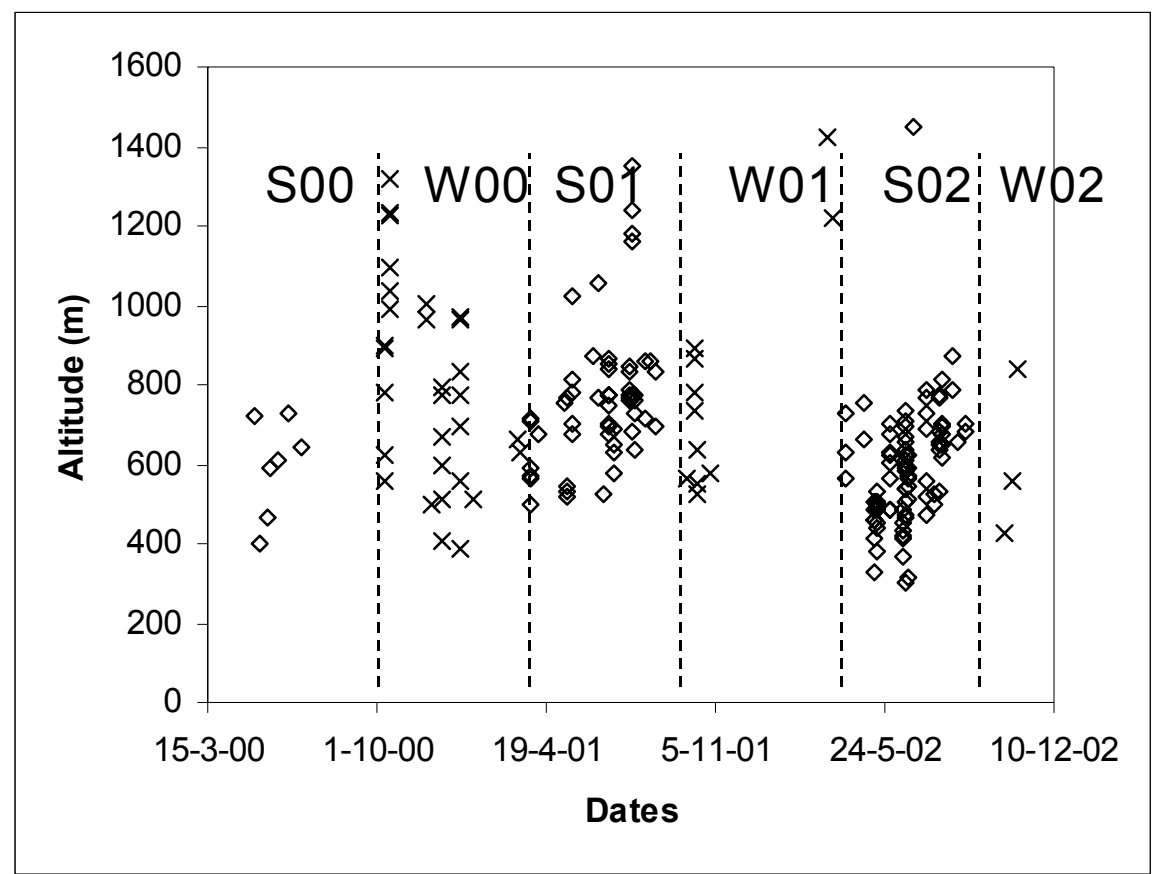

Fig. 8: Mixing layer height as a function of day of the year between 2000 and 2002. Diamonds indicate summer measurements (S) and crosses indicate winter measurements (W). 


\subsection{Limitations of the method}

We now turn to individual lidar profiles to further illustrate why and when the methods fail.

Figure 9a shows the 30-minute integrated profiles on 2 April 2001 at 1133 UTC. At 1200 UTC, the radiosounding measurement indicates a MH of $589 \mathrm{~m}$. It is obvious from Figure 9a that it is useless to look for the sharp decrease in the backscatter signal that usually characterizes the $\mathrm{MH}^{4}$. The GM and the LGM are unable to determine the MH because the ML is fully connected to the upper layers: the aerosol gradient between the ML and the upper layer is inexistent. The IPM detects a peak at $674 \mathrm{~m}$ for an inflexion point of the first derivative that is positive, i.e. the signal keeps increasing. In this particular case, the gradient of the increase at that altitude is much smaller, which could determine the transition between both layers. But this is only an assumption and therefore, even the IPM is not suitable for detecting the $\mathrm{MH}$.

Another counter example for the proposed method is the case of the 14 May 2001 (Figure $9 \mathrm{~b}$ and $9 \mathrm{c}$ ). Figure $9 \mathrm{~b}$ and $9 \mathrm{c}$ show the 30-minute integrated profiles at 0856 and 0933 UTC on 14 May 2001, respectively. That day, the 30-minute integrated results were biased by the return from some "cloudy" profiles. Figure $9 \mathrm{~b}$ shows two shallow bumps around 850 and $1000 \mathrm{~m}$, caused by the integration of a few "cloudy" profiles. The 3 methods work well and detect the MH at about $600 \mathrm{~m}$, which is consistent looking at the previous retrieved heights. However, a cloud considerably biased the next half hour of measurement and the three methods fail: the $\mathrm{MH}$ is identified as the cloud height.
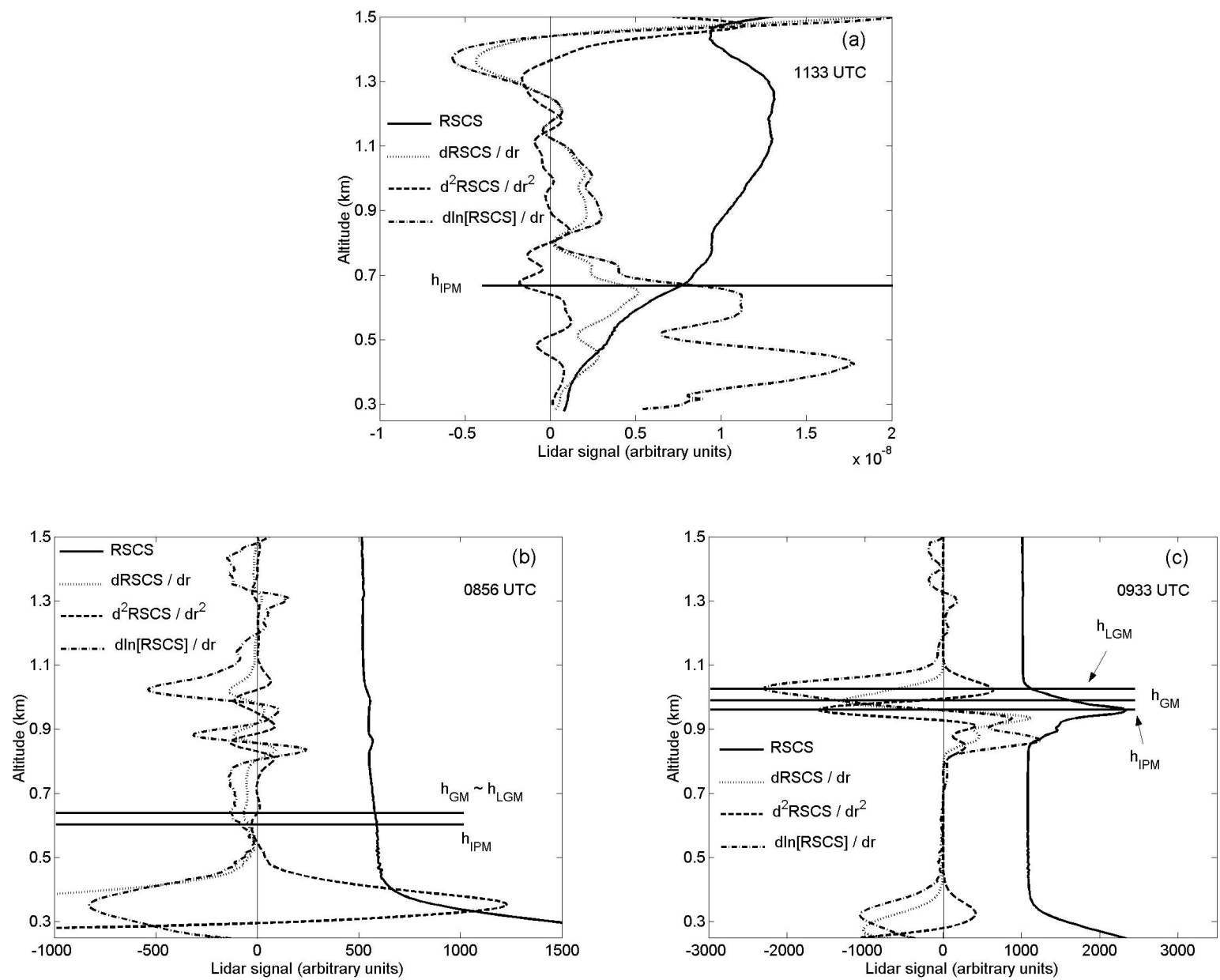

Fig. 9: Average RSCS profile over 30 minutes recorded (a) on 2 April 2001 at 1133 UTC, (b) on 14 May 2001 at 0856 UTC, and (c) on 14 May 2001 at 0933 UTC.

As a summary, limitations of the IPM are found in the presence of elevated humid aerosol-laden layers whenever the inversion capping of the mixed layer is weak. In this case, small aerosol gradients between the ML and the FT are much harder to detect than those from the elevated layers, which exhibit large aerosol and humidity gradients with respect to 
their surrounding. This phenomenon is illustrated in Fig. 9 for the late morning where we see that the MH is less marked than the top of the elevated moist layer. The IPM algorithm is designed to detect the second derivative peak, which has the greatest magnitude. In this particular case, the 2 gradient methods also fail.

Another point is that the retrieval method of the MH cannot be automated: the cross-comparison of the temporal evolution of the $\mathrm{MH}$ is a key aspect of the MH retrieval. In the global analysis described in Section 6.2., some cases were discarded because the $\mathrm{MH}$ retrieval at a specific time did not match with the $\mathrm{MH}$ retrieved from the previous and the next measurements.

\section{CONCLUSION}

The large orographic and coastal influences in Barcelona do not allow the retrieval of the MH by a classical 1-year harmonic model (in sinus or similar) and well-established MH retrieval methodologies. Three methods applicable to single lidar profiles were used to determine the ABL height. The methods are based on the determination of the strongest decrease of the backscattered lidar signal. The inflection point method (the minimum of the second derivative) gave the best results when comparing with radiosounding measurements. The two other methods give MHs a little higher, corresponding to heights in the entrainment zone, i.e. between the ML top and the beginning of the FT.

Among the 660 measurements made over 162 days, the MH during the period of maximum insolation running from 1000 to 1500 UTC oscillates between 300 and $1450 \mathrm{~m}$ in summer and between 390 and $1420 \mathrm{~m}$ in winter. Complementary data were used in almost all the cases: synoptic maps, backtrajectories, radiosoundings and solar irradiance profiles. At this period of the day, the ABL changes quite rapidly and the analysis of the 30-minute integrated profiles eventually show large differences against 5-minute and 15-minute integrated profiles. This highlights the drawback of the integration time on the MH retrieval accuracy: the IPM will only detect an "averaged" height. Limitations of the IPM are found in the presence of elevated humid aerosol-laden layers whenever the inversion capping of the mixed layer is weak: small aerosol gradients between the ML and the FT are much harder to detect than those from the elevated layers, which exhibit large aerosol and humidity gradients with respect to their surrounding. This is a significant differential trend as compared to central Europe cities such as Paris or Hamburg.

The correlation coefficient of the MH cross-comparison between lidar and radiosounding measurements among all the inter-compared methods may well be influenced by atmospheric decorrelating effects taking place over the 30-minute lidar integration time, particularly between 1000 and 1500 UTC, when the boundary layer has a stronger evolution. Thus, it is necessary that the methodological analysis includes a "discard" procedure to cope with time-punctual specific uncorrelated scenes, such as those arising in cases where some clouds are occulting the ABL top, or an aerosol layer is coupled to the ML on top of it. These situations are typical of the absence of large scale forcing due to very weak pressure gradients in Barcelona. A methodological hint arising from Section 6.1. is to increase the correlation coefficient by the temporal variance computed over the 30-minute time averaged profiles, since temporal decorrelation of the MH parameter is a major error source in some of the analyzed profiles. In summary, the analysis of complex patterns such as those occurring in Barcelona requires a progressive incorporation of new methodologies to the already existing ones along the points suggested in the examples presented in this work.

\section{ACKNOWLEDGEMENTS}

The authors wish to acknowledge the following entities for partially supporting the research work and lidar systems developed at UPC: European Union under the EARLINET contract UE EVR1-CT-1999-40003, CICYT (Spanish Interministry Commission of Science and Technology) under the grants TIC 431/93, AMB96-1144-C02-C01, TIC991050-C03-01, REN2000-1907-CE and REN2000-1754-C02-02/CLI, Spanish Ministry for Education and Culture under the Spanish-French Integrated Action HF1997-0212, and CIRIT (Interdepartmental Commission for Research and Technological Innovation, Generalitat de Catalunya) under the contract IMMPACTE. ESA is also thanked for the external postdoctoral fellowship allocated to M. Sicard.

\section{REFERENCES}

1. P. Seibert, F. Beyrich, S.E. Gryning, S. Joffre, A. Rasmussen, and P. Tercier, Mixing layer depth determination for dispersion modelling. In COST Action 710 - Final Report. Harmonisation of the pre-processing of meteorological 
data for atmospheric dispersion models, Luxembourg: Office for Official Publications of the European Communities, 1992.

2. L. Menut, C. Flamant, J. Pelon, and P. H. Flamant, Urban boundary-layer height determination from lidar measurements over the Paris area, Appl. Opt. 38, 945-954, 1999.

3. R. Boers, E. W: Eloranta, and R. L. Coulter, Lidar observations of mixed layer dynamics: tests of parametrized entrainment models of mixed layer growth rate, J. Climate Appl. Meteorol. 23, 247-266, 1984.

4. E. Dupont, J. Pelon, and C. Flamant, Study of the moist convective boundary layer structure by backscatter lidar, Boundary-layer Meteorol. 69, 1-25, 1994.

5. V. Matthias, and J. Bösenberg, Aerosol climatology for the planetar y boundary layer derived from regular lidar measurements, Atmospheric Research 63, 221-245, 2002.

6. P. Seibert, F. Beyrich, S.E. Gryning, S. Joffre, A. Ramussen, and P. Tercier, Review and intercomparison of operational methods for the determination of hte mixing height, Atmospheric Environment 34, 1001-1027, 2000.

7. J. Martín-Vide, Característiques climatològiques de la precipitació en la franja costera mediterrània de la Península Ibèrica, PhD. Thesis, Barcelona, edited by Institut Cartogràfic de Catalunya, 111-129, 1987.

8. O. Jorba, C. Pérez, J. M. Baldasano, F. Rocadenbosch, and M. A. López, Clúster análisis of backtrajectories arriving at Barcelona air basin, in $1^{\text {st }}$ EARLINET Symposium on the structure and use of the database derived from systematic lidar observations, Hamburg (Germany), 11-12 February 2003.

9. M. Millán, R. Salvador, and E. Mantilla, Photooxidant dynamics in the Mediterranean basin in summer: results from European research projects, J. of Geophys. Research 102, 8811-8823, 1997.

10. C. Soriano, J.M. Baldasano, W.T. Buttler, and K. Moore, Circulatory patterns of air pollutants within the Barcelona air basin in a summertime situation: lidar and numerical approaches, Boundary-Layer Meteorol. 98, 33-55, 2001.

11. S. Rodríguez, X. Querol, A. Alastuey, G. Kallos, and O. Kakaliagou, Saharan dust contribution to PM10 and TSP levels in Southern and Eastern Spain, Atmospheric Environment 35, 2433-2447, 2001.

12. J. Bösenberg, A. Ansmann, J.M. Baldasano, D. Balis, C. Böckmann, B. Calpini, A. Chaikovsky, P. Flamant, A. Hagard, V. Mitev, A. Papayannis, J. Pelon, D. Resendes, J. Schneider, N. Spinelli, T. Trickl, G. Vaughan, G. Visconti, and M. Wiegner, EARLINET: a European aerosol research lidar network. In Advances in Laser Remote Sensing, Ecole Polytechnique, Palaiseau, 155-158, 2001.

13. F. Rocadenbosch, C. Soriano, A. Comerón, J. M. Baldasano, A. Rodríguez, C. Muñoz, and D. García-Vizcaíno, 3D scanning portable backscatter lidar platform for atmospheric remote sensing: performance and architecture overview. In Remote Sensing of Clouds and the Atmosphere V, Proc. SPIE 4168, 158-169, 2000.

14. F. Rocadenbosch, M. Sicard, A. Comerón, J.M. Baldasano, A. Rodríguez, R. Agishev, C Muñoz, M.A. López, and D. García-Vizcaino, The UPC scanning Raman lidar: an engineering overview. In Proceedings of $21^{\text {st }}$ International Laser Radar Conference, Defence R\& D - Valcartier, Val-Bélair, 69-70, 2002.

15. W. P. Hooper, and E. W. Eloranta, Lidar measurements of wind in the planetary boundary layer: the method, accuracy and results from joint measurements with radiosonde and Kytoon, J. Climate Appl. Meteorol. 25, 9901001, 1986.

16. R. B: Stull, An introduction to boundary layer meteorology, Kluwer Academic Publishers, Dordrecht, 1988.

17. D.H.P. Vogelezang, and A.A.M. Holtslag, Evaluation and model impacts of alternative boundary-layer height formulations, Boundary-Layer Meteorol. 81, 245-269, 1996.

18. C. G. Holzworth, Mixing depths, wind speeds and air pollution potential for selected locations in the United States, J. Appl. Meteorol. 6, 1039-1044, 1967.

19. A. J. Garret, Comparison of observed mixed layer depth to model estimates using observed temperature and winds, and MOS forecasts, J. Appl. Meteorol. 20, 1277-1283, 1981.

20. R. B: Stull, Static stability - an update, Bull. Amer. Meteorol. Soc. 72, 1521-1529, 1991.

21. G. Wotawa, A. Stohl, H. Kromp-Kolb, Parametrization of the planetary boundary layer over Europe: a data comparison between the observation-based OML pre-processor and ECMWF model data, Contrib Atmos. Phys. 69, 273-284, 1996 